\title{
O riso e o corpo: reflexões acerca do riso e sua relação com o biopoder
}

\author{
RESUMO
}

Waldênia Klésia Maciel Vargas Sousa

waldeniaklesia10@hotmail.com Universidade Federal de Goiás (UFG) Goiânia, Goiás, Brasil.

\section{Eliane Marquez da Fonseca} Fernandes

elianemarquez@hotmail.com Universidade Federal de Goiás (UFG), Goiânia, Goiás, Brasil.
O objetivo deste trabalho é discutir como os enunciados a respeito do riso apresentam discursos relacionados ao corpo. Analisamos três artigos científicos publicados e coletados na internet e cuja temática volta-se para a manutenção da saúde por meio do riso. Recorremos aos estudos da Análise do Discurso de vertente francesa, com atenção aos postulados de Michel Foucault, mobilizando noções como discurso, enunciado, formação discursiva, saber, poder, sujeito, efeito de verdade, corpo e biopoder. Essas concepções permeiam toda a reflexão, com especial atenção à normalização e à regulamentação na sociedade de controle que produzem enunciados com valores discursivos relacionados ao corpo. Nas análises, evidenciamos os discursos e os saberes mobilizados nos enunciados, os quais formam a rede de exercício do biopoder sobre o corpo individual e sobre a população, para ensinar, estimular e normalizar o riso em diversas situações. Destacamos os enunciados que estabelecem efeitos de verdade em relação ao riso, baseados no saber médico, evidenciando os benefícios da repetição do ato de rir para o corpo e para a saúde. Os enunciados materializam discursos que assumem uma perspectiva positiva e prazerosa e, desse modo, constrói a subjetividade individual e coletiva, objetivando dos sujeitos docilidade e produtividade, envolvendo-os em uma rede que relaciona saberes e poderes.

PALAVRAS-CHAVE: Riso. Corpo. Discurso. Enunciado. Biopoder. 


\title{
INTRODUÇÃO
}

O riso está presente em nosso cotidiano e desempenha diversas funções, representações e maneiras de exercer determinada influência nas relações sociais. Partimos desse entendimento para estabelecer que o riso é uma prática discursiva. Assim, neste trabalho, o objetivo é interpretar e analisar alguns enunciados que interferem discursivamete no funcionamento das relações corporais e constroem a identidade dos sujeitos por meio do discurso valorativo do riso para a saúde do corpo. Para tanto, selecionamos artigos publicados no meio virtual e os analisamos à luz dos estudos da Análise do Discurso francesa e recorremos também aos escritos foucaultianos. A temática dos artigos trata dos benefícios do riso para o corpo. Entendemos esses enunciados como práticas de biopoder que visam a controlar os sujeitos por meio de seus corpos e estabelecem uma normalidade e uma anormalidade em relação à irrupção do riso em diversas situações sociais. Evidenciamos também as regularidades nas formações discursivas acerca do riso.

\section{O RISO NO LIMIAR DA HISTÓRIA}

Há diversas vertentes de estudo acerca do riso, mas é importante destacar que o estudo desse gesto percorre diversas épocas históricas. Durante os séculos XIX, XX e XXI, de acordo com Minois (2003), o riso passa por diversas alterações quanto ao seu valor e às situações nas quais era tolerado. Na Idade Média, por exemplo, há uma negatividade acerca do riso e o controle sobre esse gesto é recorrente, sendo restrito a ocasiões festivas como o Carnaval (MINOIS, 2003). O autor alerta para o fato de que há uma valorização do riso na sociedade atual e afirma que a função do riso mudou, seu aspecto alegre e, até mesmo, contestador, característicos de outros momentos históricos, como o riso carnavalesco, é discreto diante da função que o riso tem na sociedade do biopoder:

\begin{abstract}
o mundo deve rir para camuflar a perda de sentido. Ele não sabe para onde se encaminha, mas vai rindo. Ri para agarrar-se a alguma continência. Não é um riso de alegria, é o riso forçado da criança que tem medo do escuro. Tendo esgotado todas as certezas, o mundo tem medo e não quer que the digam isso; então ele fanfarreia [...], ri tolamente de qualquer coisa (MINOIS, 2003, p. 554).
\end{abstract}

Há um excesso de riso na sociedade atual e diante de tal valorização, apresentam-se várias vertentes de estudo do riso. As pesquisas e os autores que se incumbem de explicar tal fenômeno se apoiam em teorias distintas: discursiva, linguística, histórica, social, psicológica, biológica entre outros, e objetivam a explicar o riso e sua influência no comportamento humano e sua crescente valorização. Nesse contexto, destacamos os estudos de Bergson (2001), que empreende uma busca sobre os aspectos sociais que envolvem o riso. 
A obra de Bergson (2001), apesar de não ser pioneiro no tratamento desse assunto, obtém grande repercussão na época de sua publicação, pois o autor afirma que o riso é vivo e deve ser tratado com o respeito que as coisas vivas merecem. Observamos nessa afirmação o valor positivo que é atribuído ao riso. Bergson $(2001$, p. 2) afirma que o rir é humano, pois "não há comicidade fora daquilo que é propriamente humano". Para ele, a comicidade deve ser isenta de emoção, porque ela atrapalha o riso, que deve ser indiferente às tragédias sociais, e é essa indiferença que transforma as tragédias em comédia, isto é, em objeto risível.

O estudo bergsoniano prossegue destacando que o riso prolifera facilmente quando os sujeitos estão reunidos em grupo, ou seja, o riso é contagioso e tem conexão com o social. $O$ ato de rir se manifesta em sua plenitude quando o ser humano está acompanhado, entendendo que um sujeito estimula o outro a rir. Assim,

[n]ão saborearíamos a comicidade se nos sentíssemos isolados, o riso precisa de eco. [...] Nosso riso é sempre um riso de um grupo. [...] Por mais fraco que o suponham, o riso esconde uma segunda intenção de entendimento, eu diria quase de cumplicidade, com outros ridentes, reais ou imaginários. Quantas vezes já não se disse que o riso do espectador, no teatro, é tanto mais largo quanto mais cheia está a sala (BERGSON, 2001, p. 4-5).

Se considerarmos que o riso provoca ou responde a outros risos, podemos entendê-lo como uma forma de resposta ativa na enunciação. Para isso, é preciso que os sujeitos interlocutores partilhem dos mesmos valores discursivos. O "eco", a que se referem os estudos de Bergson, reitera a noção de interação evocada por Bakhtin (2006), na qual a comunicação humana é estabelecida por processos de interação verbal. Há, nesse caso, outra possiblidade de interação que ocorre por meio do riso, que se dissemina quando os sujeitos estão reunidos e interagem, isto é, um riso responde ao outro.

Bergson (2001) afirma que rir é fundamentalmente humano. Contudo, acreditamos que longe de ser uma manifestação natural da mente humana, o riso é uma prática cultural, situada historicamente e, por conseguinte, valores discursivos negativos ou positivos são agregados a esse gesto. Apesar de sua crescente irrupção na interação social na atualidade, ainda não se pode rir em qualquer lugar ou situação. Essas restrições e essas valorações indicam que o riso é discursivo e nosso estudo caminha nessa perspectiva. Aprende-se a rir e essa relação é determinada discursivamente por meio de enunciados que emergem e constituem os sujeitos. Por isso, é preciso cautela com a afirmação de que o riso é humano, correndo o risco de confundi-lo com um comportamento inato ou com uma capacidade psicológica do inconsciente sobre a qual o sujeito não tem controle.

Recorremos aos estudos bergsonianos por estabelecerem o riso a partir da perspectiva social que é constituida por meio de valores discursivos. Concordamos com Bergson (2001, p. 6) ao afirmar que "o riso deve ter uma significação social", 
pois os enunciados que pesquisamos e analisamos funcionam como discursos que estabelecem significações positivas para os sujeitos, normalizando o riso no cotidiano da população para auxiliar no prolongamento da felicidade e da boa forma.

\section{ENUNCIADO, RISO E BIOPODER}

Objetivamos analisar enunciados sobre o riso que circulam na atualidade, promovendo a valorização discursiva do riso como estratégia de biopoder, tendo como possíveis efeitos a normalização dos sujeitos. Para tanto, tomamos como centrais as noções de discurso e enunciado desenvolvidas pelos estudos foucaultianos. Nessa perspectiva, o discurso é "um conjunto de enunciados" (FOUCAULT, 2009, p. 132) e para compreendê-lo, bem como suas regras de formação, é necessário ter acesso aos enunciados. Foucault afirma que nem toda frase, proposição ou ato de fala se constitui como enunciado e argumenta que

não se requer uma construção linguística regular para formar um enunciado, mas não basta tampouco qualquer realização material de elementos linguísticos, ou qualquer emergência de signos no tempo e no espaço, para que um enunciado apareça e passe a existir. [...] o enunciado não é uma unidade do mesmo gênero da frase, proposição ou ato de linguagem (FOUCAULT, 2009, p. 97).

Assim, é necessário que haja uma materialidade efetivamente produzida por um sujeito que ocupa uma posição em determinadas condições históricas e sociais. Para Foucault (2009, p. 123), o enunciado não se confunde com uma sequência qualquer de signos linguísticos, pois o enunciado é uma função enunciativa e descrevê-lo é "definir as condições nas quais se realizou a função que deu a uma série de signos uma existência, e uma existência específica". Por conseguinte, para estudar um enunciado é fundamental remetermo-nos à função enunciativa, pois

[s]e uma proposição, uma frase, um conjunto de signos podem ser consideradas 'enunciados', não é porque houve, um dia, alguém para proferi-los ou para depositar, em algum lugar, seu traço provisório; mas sim, na medida em que pode ser assinalada a posição do sujeito. Descrever uma formulação enquanto enunciado não consiste em analisar as relações entre o autor e o que ele disser (ou quis dizer, ou disse sem querer), mas em determinar qual é a posição que pode e deve ocupar todo indivíduo para ser seu sujeito (FOUCAULT, 2009, p. 108).

Estabelecer a função enunciativa é entender que o enunciado foi proferido por um sujeito autorizado e que a situação enunciativa determina o efeito de 
sentido e atribui a um conjunto de signos, verbais ou não verbais, o estatuto de enunciado. Entendemos que não é importante quem diz, mas a posição que ocupa e que autoriza o suejito a exercer a função enunciativa. São essas as condições que possibilitam que um conjunto de signos seja entendido como um enunciado. A função enunciativa, portanto, está diretamente relacionada ao exercício do poder e ao estatuto de verdade. Essa vontade de verdade do enunciado, por sua vez, está instrinsicamente ligada aos saberes e à rede de poderes que cercam e formam os tanto os enunciados quanto os sujeitos sociais.

Os enunciados encontram-se em um meio disperso e mediante às suas regras de constituição e funcionamento discursivo, podem pertencer a uma FD. De acordo com Foucault (2009, p. 43):

\begin{abstract}
No caso em que se puder descrever, entre um certo número de enunciados, semelhante dispersão e no caso em que entre os objetos, os tipos de enunciação, o conceito, as escolhas temáticas, se puder definir uma regularidade (uma ordem, correlações, posições e funcionamentos, transformações), diremos, por convenção, que se trata de uma formação discursiva.
\end{abstract}

Uma FD não se delineia apenas por um agrupamento de enunciados que se encontram dispersos, mas por um jogo complexo envolvendo a singularidade do enunciado como acontecimento único e irrepetível e a dispersão de sentidos que tal enunciado singular pode evocar. Entendendo o discurso como um conjunto de práticas e de enunciados que recebem uma carga de valorização positiva ou negativa inferimos que, para Foucault, os dizeres sociais estão preenchidos de valores que podem ser diferentes em cada época. Assim, há momentos em que se pode rir e há momentos em que o riso é proibido. Cada vez que falamos positiva ou negativamente sobre o riso, temos um enunciado que carrega determinado valor e faz funcionar os discursos de uma FD. No entrecruzamento dos valores discursivos acessamos as FDs que também se encontram dispersas.

Os enunciados sobre o riso tecem normas de como e quando o riso pode emergir. Assim, é inapropriado rir em um velório, mas é deve-se rir ao receber um cliente que adentra ao estabelecimento comercial. Essas normas sociais mobilizam diferentes FDs. Os enunciados que controlam os comportamentos sociais estão atrelados a saberes e exercem poderes, produzem efeitos de verdade e possibitam a constituição de sujeitos que se submetem ao discurso do riso. Machado (2009) afirma que a noção de FD e suas regras estão diretamente relacionadas à constituição dos saberes e o saber está relacionado ao poder. Nessa relação, o enunciado é a unidade do discurso e seu funcionamento é delineado mediante a descrição e a análise de enunciados que compõem as FDs, para, enfim, compreender a relação entre saber e poder. É esse funcionamento enunciativo e discursivo acerca do riso que nos propomos a compreender neste trabalho.

É por meio da constante irrupção dos enunciados que carregam os valores positivos do riso que constatamos o exercício de poder nas relações sociais. 0 poder, no âmbito dos estudos foucaultianos, é entendido como produtivo, constituindo discursos e sujeitos. O poder não é exercido somente como forma de adestramento, ou seja, ele não se apresenta como modo de escravizar o sujeito, 
tirando sua liberdade, mas constrói subjetividades propensas ao riso. Dessa maneira, o riso não é cobrado de modo coercitivo ou violento, mas, por meio de enunciados que visam a subjetivar os sujeitos a rir constantemente e a cobrar o riso dos demais. De acordo com Foucault,

[o] que faz com que o poder seja aceito é simplesmente que ele não pesa só como uma força que diz não, mas que de fato ele permeia, produz coisas, induz ao prazer, forma saber, produz discurso. Deve-se considerá-lo como uma rede produtiva que atravessa todo o corpo social muito mais do que uma instância negativa que tem por função reprimir (2010b, p. 8).

Para Foucault, o poder não emana apenas de instâncias superiores como instituições jurídicas ou do Estado, mas está em uma relação dialética entre os sujeitos, dissemina-se nos detalhes da vida cotidiana. Por isso, se alguém sorri ao cumprimentar um colega e não recebe um riso como resposta, logo se questiona acerca da alteração da normalidade, pois a ausência de um sorriso como resposta desestabiliza o interlocutor. Esse funcionamento discursivo ocorre porque o poder não tem somente por função reprimir, ele é produtivo, visa o bem-estar individual e social. Além disso, não há um sujeito que esteja neutro em relação ao exercício do poder que forma sua consciência, cria sua individualidade e potencializa suas ações e capacidades. Os discursos que valorizam o riso e evidenciam seus benefícios para o corpo, a saúde, a longevidade e a beleza dos sujeitos tornam-se cada vez mais populares e constituem um modo de exercício de poder que emerge por meio de diversos enunciados. Foucault (1995, p. 243) afirma que o poder é um

[...] conjunto de ações sobre ações possíveis; ele opera sobre o campo de possibilidade onde se inscreve o comportamento dos sujeitos ativos; ele incita, induz, desvia, facilita ou torna mais difícil, amplia ou limita, torna mais ou menos provável; no limite, ele coage ou impede absolutamente, mas é sempre uma maneira de agir sobre um ou vários sujeitos ativos, e o quanto eles agem ou são suscetíveis de agir. Uma ação sobre ações.

Observamos que a proposta foucaultiana é demonstrar que o poder pode circular nas diversas instâncias e na multiplicidade de campos da vida social cotidiana. Essa proposta evidencia como as relações sociais estão preenchidas de maior ou menor exercício de poder. A sociedade é constituída por meio de enunciados e de práticas que padronizam os comportamentos dos sujeitos e, por isso, podemos dizer que há um poder que conduz à aceitação e ao comprometimento com os valores padronizados. Os sujeitos podem adotar valores como rir com maior frequência porque são estimulados a isso por meio do discurso.

A sociedade que se delineia a partir do fim do século XVIII está voltada para o controle da vida. Esse controle social também pressupõe o controle do corpo para manter a saúde e, consequentemente, a vida. É, portanto, uma sociedade regida pelas estratégias do biopoder. O bem-estar, a saúde e a felicidade do sujeito é uma maneira de fazer a vida se prolongar e entre os mecanismos discursivos 
encontrados para cumprir o objetivo de fazer o sujeito feliz está o ato de rir, que se apresenta, atualmente, como uma questão de saúde pública. Esse poder se ampara em diversos saberes que visam a comprovar que o riso traz benefício para a saúde, para a vida e para o corpo das pessoas.

O biopoder se aplica à "vida dos homens, ou ainda, [...] ela se dirige não ao homem-corpo, mas ao homem vivo, ao homem ser vivo" (FOUCAULT, 1999, p. 289). O biopoder controla a vida feliz dos homens, pois há uma resistência ao comportamento sério que, de acordo com os enunciados que circulam, pode ser sintoma de problemas psicológicos ou físicos. De acordo com Machado (2010, p. XXII), toda felicidade social tem o objetivo de "gerir a vida do corpo social". Desse modo, se a sociedade aceita o riso como normal, significa que há um processo de nornalização que engendra e faz funcionar o discurso de valorização do riso e da felicidade constante. Logo, o discurso tem um poder de persuação sobre os comportamentos sociais da população.

Foucault (1999, p. 294) afirma que a regulamentação é uma estratégia de biopoder que procura obter "estados globais de equilíbrio, de regularidade; em resumo, de levar em conta a vida, os processos biológicos do homem-espécie e de assegurar sobre eles não uma disciplina, mas uma regulamentação". Trata-se de tentar estabelecer uma homogeneidade na população, nivelar os sujeitos em torno de estatíscas equilibradas que objetivam assegurar a vida. Busca-se a segurança em relação àquilo que pode colocar a vida em perigo, causando a mortalidade do corpo, tais como acidentes, doenças e comportamentos prejudiciais à saúde em geral, como depressões, tristezas, estresse, entre outros males elencados nos enunciados que irrompem na atualidade.

\section{O RISO E O CORPO}

É difícil contestar que o riso é valorizado na sociedade atual e relaciona-se ao modo de viver dos sujeitos. São inúmeras as situações nas quais é importante rir: para o cliente que chega à loja; no ambiente corporativo; nos programas televisivos e jornalísticos; em ambientes hospitalares auxiliando a cura do paciente. Porém, vale descatar que o discurso sobre o riso não é unânime, há resistências, pois cada sujeito tem a subjetividade constituída por várias FDs. Todavia, devido ao espaço disponível para desenvolver as reflexões não tratamos de tais resistências, pois nosso objetivo é analisar a construção discursiva posisitva acerca riso sobre o corpo individual e social, como forma de normalização do riso. Assim, procuramos especificar algumas estratégias discursivas encontradas no corpus selecionado, que apresenta como regularidade a importância e eficácia do riso para a saúde e o corpo dos sujeitos, estabelecendo normas a fim de promover o bem-estar coletivo.

Os artigos analisados mobilizam saberes de diversas FDs que atribuem ao riso poderes preventivos e curativos para o corpo. Esses saberes têm estatuto de verdade, pois veiculam estudos científicos e objetivam mostrar que o riso traz benefícios para o ser humano e se dirigem diretamente ao corpo dos sujeitos de acordo com os enunciados que circulam atualmente. Portanto, constatamos que $o$ discurso acerca do riso não está associado somente a momentos de descontração ou festividade, mas é um gesto normativo que auxilia na garantia de saúde física e mental da população cotidianamente. 
Conforme afirma Foucault (1988), o biopoder se articula nas diferentes esferas da vida humana e visa a intervir nas ínfimas ações do sujeito que devem ser acompanhadas do riso, isto é, as ações realizadas pelos sujeitos devem ser realizadas de forma prazerosa, tendo em vista o ritmo frenético do cotidiano, que causa malefícios ao corpo, conforme encontramos no excerto:

Na correria do dia-a-dia, é muito comum nos estressarmos com os empecilhos da rotina ou ficarmos extremamente cansados no fim do dia, sem vontade de fazer nada. Embora pareçam não ter remédio, esses males podem ter uma solução muito simples: sorrir! É de graça e você não precisa de mais nada além de você mesmo para isso (Conheça 11 benefícios que o sorriso traz para a sua saúde, 2011, ANEXO A).

Destacando os aspectos negativos da vida urbana atual, tais como o estresse, o cansaço e o desânimo, delineia-se um reforço do aspecto positivo do riso, que é capaz de livrar os sujeitos desses malefícios. Vemos a utilização de dois saberes distintos e complementares, o primeiro, que indica os males da vida moderna e o segundo que promete solucionar os problemas incluindo o riso na rotina. Outro destaque pode ser feito em relação aos gastos com tratamentos de saúde causados pelo estresse, sendo o riso um remédio gratuito, demonstrando a facilidade que se tem para prevenir e curar prováveis males. Então, mobiliza-se nesse excerto saberes de FDs distinas como a medicina e a economia. Esses diferentes saberes são mobilizados a fim de estabelecerem um jogo de poder na sociedade voltada para o capital financeiro, que valoriza a saúde com a finalidade de obter recursos econômicos prolongando a utilidade da vida. Esse entendimento é ratificado por Foucault (1988) acerca do surgimento do biopoder relacionado ao aparecimento do Capitalismo por volta do século XVIII. Assim, se o sujeito se identifica com tais enunciados, passará a disseminar esse discurso positivo sobre o riso, objetivando controlar a ação dos demais sujeitos. Retomamos Foucault (2010a) que se refere ao poder como uma ação sobre a ação dos outros. Ainda nesse trecho é possível observar a sugestão de que não é preciso motivos exteriores para rir, mas deve ser um hábito, um comportamento constante, isto é, é preciso estar propenso ao riso como ação cotidiana.

O riso como norma se estabelece relacionado constantemente ao saber clínico. Os enunciados analisados mobilizam a FD da medicina para reforçar a ideia de que o riso é positivo do ponto de vista biológico. Observamos que os discursos materializados nesses enunciados voltam-se para o corpo dos sujeitos, evidenciando que deve-se rir não apenas quando se tem vontade, é preciso buscar maneiras de tornar o riso constante para que se obtenha benefícios corporais: "há evidências de que após uma boa sessão de riso temos redução do nível de ansiedade, relaxamento de grupos musculares e redução da excitabilidade da medula espinhal" (Conheça 11 benefícios que o sorriso traz para a sua saúde, 2011, ANEXO A). Além disso, o termo 'boa' revela que um riso contido não é adequado, mas o riso deve ser intenso para que os benfícios possam surgir.

Os discursos que envolvem a população visando a normalizá-la cuidando da vida e da saúde, de acordo com Foucault (1999, p. 293), tendem a "fixar um equilíbrio, manter uma média". Assim, em outro trecho dos dados percebemos dizeres que também valorizam o riso que "pode trazer equilíbrio a todos os componentes do sistema imunológico, sistema que nos ajuda a lutar contra as 
doenças" (Riso e saúde, 2011, ANEXO B). Não se trata apenas de sugerir que o riso é bom. Os saberes sobre o riso exercem poder na sociedade atual porque preservam seu bem mais precioso: a vida. Com esse objetivo, a ciência médica investe em pesquisas que comprovam a eficácia de rir e os meios de comunicação se incumbem de disseminar essas verdades discursivas. Sob o estatuto de verdade comprovada por métodos científicos os enunciados não devem ser questionados. A combinação entre saber e verdade aumenta o controle desse discurso sobre o corpo em quaquer época da vida. Em outro excerto, temos o riso auxiliando os sujeitos a terem velhice produtiva, enfatizando novamente a relação riso e corpo em diversas faixas etárias:

\begin{abstract}
uma pesquisa feita pela equipe da Universidade de Loma Linda, uma gargalhada é tão saudável quanto a prática de exercícios físicos. Isso porque ela estimula a circulação, produz endorfina e também movimenta nossos músculos, não só do abdômen, mas das pernas, braços e pés. Os pesquisadores afirmaram que o riso pode ser a chave para a saúde de idosos que não conseguem praticar atividades físicas (Conheça 11 benefícios que o sorriso traz para a sua saúde, 2011, ANEXO A).
\end{abstract}

Outra evidência de que o riso e o corpo estão relacionados por meio do discurso é a materialização de enunciados que apregoam sua relação para a beleza, pois os músculos faciais são estimulados e diminuiem as rugas, cuja aparição é motivo de preocupação, pois as marcas na pele evidenciam que o sujeito está envelhecendo e a morte se aproxima. Parecer velho é negativo para o sujeito e o riso promete ter efeitos rejuvenecedores. Desse modo, não apenas a saúde do corpo emerge como temáticas nos enunciados, mas a busca pela beleza e pela juventude também:

Ao dar boas risadas, nós movimentamos 12 músculos faciais e, ao dar gargalhadas, movimentamos 24 desses músculos. Quando conversamos e gargalhamos ao mesmo tempo, então, são 84 músculos. Todo esse exercício facial estica a pele, retardando o aparecimento de rugas (Conheça 11 benefícios que o sorriso traz para a sua saúde, 2011, ANEXO A).

Sobre a aparência do sorriso e sua influência no corpo e na saúde dos sujeitos, temos:

[q]uanto mais profundos os vincos em volta dos olhos quando se sorri, mais longa será a vida do indivíduo. Quanto mais largo o sorriso e mais profundos os vincos em volta dos olhos quando se sorri, mais longa será a vida do indivíduo, revela um estudo publicado esta semana na revista Psychological Science (Um sorriso largo garante uma vida longa, revela estudo, 2011, ANEXO C).

Esse enunciado denota que não é qualquer sorriso que deve emergir e, por isso, não se deseja controlar apenas a frequência do riso, mas também sua extensão e duração. O controle sobre o corpo do sujeito se evidencia até na gradação de pequenos gestos como o vinco dos olhos enquanto o sujeito ri. Os discursos visam a controlar todos os aspcetos relacionados ao riso como forma de controlar o sujeito. $O$ estudo realizado com 230 fotos de jogadores da principal liga de beisebol americana que começaram a jogar antes de 1950, ressaltando 
informações relevantes para refletirmos sobre a relação do corpo e do riso e estabelece uma norma: quanto maior for o sorriso, maior a expectativa de vida. Entedemos que a forma e a gradação do sorriso se constituem em um modo de classificação dos sujeitos entre normais e anormais. No trecho seguinte, entendemos que os sujeitos 'sem sorriso' são vistos de modo negativo, pois viveram menos do que os outros dois grupos de pessoas que riam e, consequentemente, viveram mais e são, portanto, considerados como normais:

Os jogadores foram classificados segundo os critérios "sem sorriso" quando apenas olhavam inexpressivamente para a câmera -, "sorriso parcial" - quando o sorriso envolvia apenas os músculos ao redor da boca - ou "sorriso total", quando o sorriso envolvia a boca, os olhos e ambas as bochechas pareciam levantadas. [...] Entre os jogadores falecidos a partir de 10 de junho do ano passado, os da categoria "sem sorriso" viveram uma média de 72,9 anos, os com "sorriso parcial", 75 anos, e os de "sorriso total" viveram, em média, 79,9 anos, demonstrou o estudo (Um sorriso largo garante uma vida longa, revela estudo, ANEXO C, 2011).

Os discursos acerca da tristeza e da depressão são alvos do biopoder, pois os estudos científicos que constam no corpus indicam que esses fatores diminuem a vida e a produtividade dos sujeitos. Os enunciados que circulam demonstram que a maneira de combater esses males é rir vigorosamente, como se o ato de rir realmente fosse o remédio para todos os males. O biopoder, para Foucault (1988), é essa pressão social com a qual convivemos acerca e reforlam a importância do bem-estar e da necessidade de uma vida saudável do ponto de vista biológico. Assim, os enunciados que carregam valores acerca da longevidade do corpo proporcionados pelo riso estão na ordem do biopoder. Com isso, passamos a ver o aconselhamento sobre o riso como uma estratégia de exercício de biopoder que visa a normalizar os sujeitos a rir frequentemente.

Outros excertos mobilizam saberes relacionados à medicina psíquica, como vemos em: "Cada vez mais os profissionais de saúde mental estão sugerindo a 'terapia do riso', que ensina às pessoas como rir abertamente de coisas que normalmente não são engraçadas, e a enfrentar situações difíceis usando o humor" (Riso e saúde, 2011, ANEXO B). Rir de algo que normalmente não é engraçado mobiliza a positividade em torno da qual se alicerça toda a discussão sobre o riso, negando sentimentos ruins diante de problemas do cotidiano, ou seja, é negativo, do ponto de vista discursivo, ficar triste. No entanto, é preciso treinar e disciplinar o riso e as técnicas de risoterapia não epenas exaltam o ato de rir como também educam para o riso.

Há discursos contrários à necessidade de rir, isto é, há resistências. No entanto, o exercício do poder tenta silenciar tais restistências que podem desautorizar a positividade do riso e seus benefícios para a população. Para reforçar a positividade e produtividade do riso, lança-se mão de diversas estratégias para aumentar a frequência com que o sujeito deve rir como, por exemplo, como participar de sessões de terapia do riso ou cercar-se de outros sujeitos que também riam. O padrão social é o riso, tanto que devemos rir diante de diversas situações, porque esse hábito ajuda a separar os normais dos anormais. 
O caminho percorrido até aqui demonstram que os enunciados relacionam-se principalmente à FD da medicina, pois o discurso sobre a manutenção da vida está ligado, inevitavelmente, à saúde da população. Por isso, a fim de garantir bons resultados para a saúde e para o prolongamento da vida, os sujeitos são lembrados do quanto é saudável rir. Conforme Foucault (1988), o biopoder se articula nas diferentes esferas da vida humana, com a finalidade de alcançar bons índices de qualidade de vida:

Já sabemos há muito tempo que rir é útil para aqueles que enfrentam uma doença grave e o estresse dos problemas da vida. Mas os pesquisadores agora dizem que o riso pode fazer muito mais. Basicamente, ele pode trazer equilíbrio a todos os componentes do sistema imunológico, sistema que nos ajuda a lutar contra as doenças (Riso e saúde, 2011, ANEXO B).

Nesse enunciado, percebe-se que o grande investimento na ciência médica no desenvolvimento de pesquisas que comprovem a eficácia do riso. Os meios de comunicação se incumbem de disseminar essas verdades "reveladas" pelas pesquisas que são discursos autorizados e aceitos pelos sujeitos. Essa combinação entre saber e verdade possibilita maior controle do riso sobre a vida. Outros benefícios do riso para o corpo podem ser encontrados no excerto:

Antes de assistir a cada filme, os voluntários ficavam em jejum e submetiam-se a testes para saber como vasos sanguíneos respondiam a súbitos aumentos no fluxo de sangue. Ao final do estudo, foi revelado que o estresse reduz o fluxo de sangue em $35 \%$. Já as risadas provocadas pela comédia fizeram com que o fluxo aumentasse $22 \%$, reduzindo a pressão arterial. Paralelo a isso, ocorria uma limpeza dos vasos sanguíneos (Conheça 11 benefícios que o sorriso traz para a sua saúde, 2011, ANEXO A).

O trecho faz referência a um estudo científico realizado com diversos indivíduos que foram submetidos a sessões de filmes de comédia. Os resultados foram positivos para a saúde de todos aqueles que se submeteram ao riso. $O$ uso do pronome indefinido "todos" reforça que a norma é rir, não se deve ficar sério. Nos enunciados "o estresse reduz o fluxo de sangue" e "já as risadas provocadas pela comédia fizeram com que o fluxo aumentasse", percebemos o destaque benéfico que se atribui ao riso em detrimento dos efeitos nocivos que o estresse pode causar. $\mathrm{O}$ uso de vocábulos médicos ratifica o efeito de verdade e a estratégia de normalização do riso, construindo um discurso de autoridade advindo da cientificidade.

O reforço do discurso que acentua os benefícios do riso cria uma atmosfera que induz o sujeito a rir para viver e para produzir mais. No trecho anterior, estabelece-se uma comparação entre os resultados de pacientes que foram submetidos a seções de gargalhadas e obtiveram melhorias em relação aos pacientes que realizaram o tratamento padrão para hipertensão arterial, isto é, todos estão doentes, mas aqueles que riram, melhoraram. Os dados estatísticos são mecanismos do biopoder para medir a eficâcia dos dispositivos de controle da vida. São dois grupos de indivíduos que demonstram que quem não rir terá consequências ruins. Não basta recorrer à medicina, mas deve-se recorrer ao riso que tem poder curativo e auxilia nos tratamentos médicos: 
Metade desses pacientes continuou com o tratamento padrão, enquanto a outra metade, além de tomar a medicação, assistia a filmes de comédia diariamente, durante 30 minutos. Após um ano, o grupo que foi estimulado a gargalhar elevou seus níveis de HDL, o bom colesterol, em até $26 \%$. No grupo de controle o aumento foi de apenas 3\% (Conheça 11 benefícios que o sorriso traz para a sua saúde, 2011, ANEXO A).

Para Foucault (1999), o biopoder, que é uma nova maneira de exercer o poder que conduz o sujeito intimamente, afastando-o de comportamentos que podem levá-lo mais rapidamente à morte como, por exemplo, ser uma pessoa séria, sisuda. Considerando os valores de normalidade positiva do riso para garantir que o sujeito sorria constantemente, há uma vigilância da sociedade. Essa cobrança emerge como 'dicas' que visam a ensinar o sujeito a cercar-se de instrumentos que suscitem o riso e torne padrão:

Aqui vão algumas dicas para você acrescentar mais riso à sua vida:

- descubra o que faz você rir e faça isto (ou leia ou assista isto) mais frequentemente;

- cerque-se de pessoas engraçadas e esteja com elas sempre que puder;

- desenvolva o seu próprio senso de humor.

Você pode até ter aulas para aprender como ser um humorista melhor ou pelo menos um contador de piadas melhor na próxima festa (Riso e saúde, 2011, ANEXO B).

Essas 'dicas' são alguns dos enunciados recorrentes e tendem a subjetivar o sujeito, normalizando o riso e instaurando a tecnologia do biopoder. $\mathrm{O}$ uso de verbos no modo imperativo denota o tom de discurso normativo. Quando o autor utiliza os verbos os "descubra", "cerque-se" e "desenvolva" se referindo a tais atos como "dicas", delineia-se uma sequência de normas, ordens, ou um manual de como fazer para rir mais, mesmo quando não se tem vontade. $O$ trecho anterior é uma receita do riso fácil, incialmente tendo a conotação de recomendação. É assim que se comportam as estratégias de exercício de poder, que condicionam o sujeito. Os discursos não são formas de adestramento ou repressão, mas conduzem o indivíduo a acreditar e se filiar a alguns saberes e rejeitar outros. Subjetivado, o sujeito pode disseminar esses discursos e compartilhar os valores positivos do riso com todos ao seu redor e, inclusive, cobrando desses outros um comportamento parecido, construindo a rede de exercício de poder.

A regulamentação do riso é respaldada por saberes médicos, em vozes de autoridade e em estudos comprobatórios de sua eficácia. Os discursos afirmam que, para ser realmente benéfico, é vital a repetição do ato de rir. Foucault (1999) afirma que um bom exemplo do poder que busca gerir a vida é o estudo estatístico de tudo o que é relacionado à vida e à morte da população. Procura-se medir, calcular e estudar as possibilidades para apresentar resultados precisos comprovados por discursos considerados confiáveis. Essa estratégia também mas de um lugar autorizado e respeitável. Observamos nos artigos um destaque a 
instituições científicas para atribuir estatuto de verdade ao que diz: "Cientistas chefiados por Ernest Abel, da Universidade Wayne State, em Michigan" (Um sorriso largo garante uma vida longa, revela estudo, 2011, ANEXO C); "Uma pesquisa na Universidade de Loma Linda, na Califórnia (EUA)" e " $O$ sorriso melhora o bom humor, eleva a autoestima e te deixa mais seguro', diz a psicóloga Melina Blanco Amarins, do Hospital Albert Einstein" (Conheça 11 benefícios que o sorriso traz para a sua saúde, 2011, ANEXO A). É notável como o discurso científico é valorizado e os enunciados acerca do riso estão apoiados nesses saberes a fim de possibilitar a circulação de poderes que interferem diretamente na materialidade imediata do sujeito: o corpo.

\section{CONSIDERAÇÕES FINAIS}

Os dados coletados e analisados mobilizam principalmente a noção de biopoder (FOUCAULT, 1988). Assim, os enunciados não só induzem ao riso, mas também tentam estabelecer uma normatividade para a sociedade. Concordamos com Foucault (2010a) ao afirmar que o exercício de poder não é apenas repressor e violento, dizendo sempre não, mas é produtivo e sutil e pode emergir como um riso em determinada situação. Desse modo, os enunciados analisados mobilizam discursos de enaltecimento ao riso e esses dizeres estão interligados formando uma rede que cerca o sujeito, incidindo em sua materialidade imediata: o corpo. O sujeito está imerso em uma rede de saberes que emergem por meio de enunciados proferidos por vozes de autoridade, enaltecendo os benefícios do riso para a vida, a saúde e a beleza da população.

Cremos que essa atmosfera positiva acerca do discurso sobre o riso são estratégias de biopoder, que mobilizam saberes de diversas FDs como a medicina, principalmente. Entendemos, assim, que a pressão constante exercida por essa rede de saberes e poderes pode ser eficaz para constituir os sujeitos, controlar suas ações e até os íntimos detalhes do cotidiano que incidem sobre seus corpos. Atualmente, o riso exerce uma função normalizadora, formando o sujeito como corpo dócil e produtivo, prometendo também o prolongamento e a qualidade de vida. As práticas que envolvem o riso estão ligadas a saberes científicos, como aqueles que indicam que pessoas felizes vivem mais e melhor ou que um sorriso pode auxiliar na cura de doenças.

Enfim, salientamos que este trabalho é uma proposta para refletir sobre a relação entre o biopoder, o riso e o corpo. Sabemos que há discursos contrários à valorização do riso, porém, a proposta deste artigo é discutir os mecanismos discursivos utilizados para a construção de uma positividade acerca do ato de rir. Analisar os discursos contrários é uma tarefa que está por fazer. Outrossim, por meio dessas reflexões, esperamos contribuir com os estudos linguísticos voltados para o discurso, em especial, com a Análise de Discurso de vertente francesa, com recorrência aos estudos de Michel Foucault. 


\title{
Laugh and body: reflections on laughing and its relations with biopower
}

\begin{abstract}
The aim of this paper is to discuss how statements about laughter feature speeches related to the body. We analyze three scientific papers published and collected on the Internet and whose subject turns to the maintenance of health through laughter. We appealed to the studies of the French aspect of discourse analysis, with attention to Michel Foucault's postulates, mobilizing notions such as speech, statement, discursive formation, knowledge, power, subject, truth effect, body and biopower. These views pervade reflection, with special attention to standardization and regulation on the control of society that produce statements with discursive values related to the body. In the analyzes, we noted the speeches and the knowledge mobilized in the statements, which make up the biopower exercise network on the individual body and the population, to teach, encourage and normalize laughter in various situations. We highlight the statements that establish real effects in relation to laughter, based on medical knowledge, highlighting the benefits of repeating the act of laughing for the body and health. The statements materialize discourses that take a positive and pleasant perspective and thus builds individual and collective subjectivity, aiming subjects docility and productivity by involving them in a network that links knowledge and power.
\end{abstract}

KEYWORDS: Laughter. Body. Speech. Statement. Biopower. 


\section{REFERÊNCIAS}

BAKHTIN, M./VOLOCHINOV. Marxismo e Filosofia da Linguagem. Traduzido por Michel Lahud e Yara Frateschi. 12. ed. São Paulo: Hucitec, 2006.

BERGSON, H. O riso: ensaio sobre a significação da comicidade. Tradução de Ivone Castilho Benedetti. São Paulo: Martins Fontes, 2001.

Conheça 11 benefícios que o sorriso traz para a sua saúde: rir fortalece o sistema imunológico, combate o estresse e elimina rugas. Disponível em: <http://www.minhavida.com.br/bem-estar/galerias/13491-11-beneficios-que-oriso-traz- para-a-sua-saude>. Acesso em: 26 abr. 2014.

FOUCAULT, M. História da sexualidade I: a vontade de saber. Tradução Maria Tereza da Costa Albuquerque e J.A. Guilhon Albuquerque. Rio de Janeiro: Graal, 1988.

O Sujeito e o poder. In: DREYFUS, R; RABINOW, P. Michel Foucault: uma trajetória filosófica (para além do estruturalismo e da hermenêutica). Tradução de Vera Porto Carrero. Rio de Janeiro: Forense Universitária, 1995, p. 229-249.

Aula de 17 de março de 1976. In: Em defesa da sociedade: curso no Collège de France (1975-1976). Tradução M. E. Galvão. São Paulo: Martins Fontes, 1999, p. 285-315.

A arqueologia do saber. Tradução Luiz Felipe Baeta Neves. 7. ed. Rio de Janeiro: Forense Universitária, 2009.

Estratégia, poder-saber (Ditos e Escritos IV). Org. e seleção de textos M. B. Motta. Tradução V. L. A. Ribeiro. 2. ed. Rio de Janeiro: Forense Universitária, 2010a.

Microfísica do poder. Tradução e organização. Roberto Machado. Rio de Janeiro: Graal, 2010b.

MACHADO, R. Foucault, a ciência e o saber. 4. ed. Rio de Janeiro: Jorge Zahar, 2009.

. Introdução: Por uma genealogia do poder. In: FOUCAULT, M. Microfísica do Poder. Tradução e organização Roberto Machado. Rio de Janeiro: Graal, 2010. 
MINOIS, G. História do riso e do escárnio. Tradução Maria Helena Ortiz Assumpção. São Paulo: UNESP, 2003.

Riso e saúde. Disponível em: <http://saude.hsw.uol.com.br/riso7.htm>. Acesso em 11 de dez. de 2011.

Um sorriso largo garante uma vida longa, revela estudo. Disponível em: $<$ http://noticias.uol.com.br/ultnot/cienciaesaude/ultimasnoticias/afp/2010/03/26/um-sorriso-largo-garante-uma-vida-longa-revelaestudo.jhtm>. Acesso em: 17/05/2014.

\section{ANEXO A}

Conheça 11 benefícios que o sorriso traz para a sua saúde

Rir fortalece o sistema imunológico, combate o estresse e elimina rugas

Na correria do dia a dia, é muito comum nos estressarmos com os empecilhos da rotina ou ficarmos extremamente cansados no fim do dia, sem vontade de fazer nada. Embora pareçam não ter remédio, esses males podem ter uma solução muito simples: sorrir! É de graça e você não precisa de mais nada além de você mesmo para isso.

O riso, além de trazer aquela sensação de bem-estar que todo mundo conhece, pode ser um grande aliado da saúde, ajudando a prevenir doenças e auxiliando o organismo a cumprir as suas funções diárias. É benefício da cabeça aos pés! Veja aqui tudo o que uma boa gargalhada pode fazer por você.

\section{Coração}

Uma pesquisa na Universidade de Loma Linda, na Califórnia (EUA), afirma que o riso pode reduzir o risco de doenças cardíacas. A equipe separou dois grupos de pessoas que tinham sofrido um ataque cardíaco e estavam sob cuidados médicos. O primeiro grupo assistia a vídeos de humor durante 20 minutos, todos os dias.

Após um ano, esse grupo apresentou uma queda de $66 \%$ da proteína C-reativa, que é um marcador da inflamação e do risco de problemas cardiovasculares. A queda dessa substância no outro grupo foi de apenas $26 \%$. Como conclusão, as pessoas que riram mais tiveram o risco de problemas cardíacos reduzido significativamente.

Colesterol e diabetes

Dar boas risadas pode aumentar os níveis de colesterol bom no sangue, de acordo com uma pesquisa realizada na Universidade Loma Linda. Os pesquisadores acompanharam 20 pacientes diabéticos com altas taxas de colesterol ruim no sangue. Todos usavam remédios para controlar esses problemas.

Metade desses pacientes continuou com o tratamento padrão, enquanto a outra metade, além de tomar a medicação, assistia a filmes de comédia diariamente, durante 30 minutos. Após um ano, o grupo que foi estimulado a gargalhar elevou 
seus níveis de HDL, o bom colesterol, em até $26 \%$. No grupo de controle o aumento foi de apenas $3 \%$.

\section{Pressão arterial}

Um estudo realizado na escola de medicina da Universidade de Baltimore, nos Estados Unidos, descobriu que rir diminui a pressão arterial, enquanto o estresse a aumenta. A equipe estudou 20 voluntários saudáveis, não fumantes, com idade média de 33 anos. Eles assistiam primeiro a um trecho de um filme que causasse estresse e, 48 horas depois, viam um filme de comédia.

Antes de assistir a cada filme, os voluntários ficavam em jejum e submetiam-se a testes para saber como vasos sanguíneos respondiam a súbitos aumentos no fluxo de sangue. Ao final do estudo, foi revelado que o estresse reduz o fluxo de sangue em $35 \%$. Já as risadas provocadas pela comédia fizeram com que o fluxo aumentasse $22 \%$, reduzindo a pressão arterial. Paralelo a isso, ocorria uma limpeza dos vasos sanguíneos.

Pulmões

De acordo com a especialista em terapia do riso Conceição Trucom, dona do site Doce Limão, quando damos uma boa gargalhada, a absorção de oxigênio pelos pulmões aumenta. Inalamos mais ar e, com isso, a expiração também fica mais forte. "Com maior ventilação pulmonar, o excesso de dióxido de carbono e vapores residuais é rapidamente eliminado, promovendo uma limpeza ou desintoxicação". Ou seja, rir limpa os seus pulmões e ainda os deixa mais fortes!

\section{Digestão}

De acordo com a psicóloga Fátima Niemeyer, da Sociedade Brasileira de Psicologia, os músculos que são mais estimulados quando rimos são os abdominais. Esses movimentos fazem uma espécie de massagem em nosso sistema gastrointestinal, melhorando a digestão. "Essa massagem também revigora todo o trabalho hepático", diz Conceição.

Circulação do sangue

O ritmo cardíaco acelera quando começamos a rir. Os batimentos podem atingir até 120 pulsações por minuto, em comparação com as 70 pulsações por minuto quando estamos em repouso. "Quando a pulsação aumenta, o sangue circula mais intensamente no organismo, o que aumenta a oxigenação de todas as células, tecidos e órgãos", afirma Fátima. Isso faz com que nosso organismo funcione a todo vapor!

Estresse e sistema imunológico

"Durante uma sessão de gargalhadas, os níveis de cortisol e adrenalina - hormônios do estresse - baixam", diz Conceição. Além disso, nosso cérebro passa a produzir endorfina, hormônio que nos deixa relaxado.

Isso faz com que o corpo consiga produzir mais células de defesa, que ficam mais ativas, fortalecendo o sistema imunológico e blindando o organismo contra doenças. Segundo Conceição, as células que ganham vantagem na produção quando os níveis de estresse abaixam - são os linfócitos B, responsáveis pela produção de anticorpos; os linfócitos $T$, que são verdadeiros rastreadores de vírus e bactérias; a imunoglobina $A$, um anticorpo essencial no combate às infecções respiratórias; e as células NK, que são destruidoras de células cancerígenas. 


\section{Combate as rugas}

Ao dar boas risadas, nós movimentamos 12 músculos faciais e, ao dar gargalhadas, movimentamos 24 desses músculos. Quando conversamos e gargalhamos ao mesmo tempo, então, são 84 músculos. Todo esse exercício facial estica a pele, retardando o aparecimento de rugas.

\section{Exercício físico para os idosos}

De acordo com uma pesquisa feita pela equipe da Universidade de Loma Linda, uma gargalhada é tão saudável quanto a prática de exercícios físicos. Isso porque ela estimula a circulação, produz endorfina e também movimenta nossos músculos, não só do abdômen, mas das pernas, braços e pés. Os pesquisadores afirmaram que o riso pode ser a chave para a saúde de idosos que não conseguem praticar atividades físicas.

\section{Autoestima}

"O sorriso melhora o bom humor, eleva a autoestima te deixa mais seguro", diz a psicóloga Melina Blanco Amarins, do Hospital Albert Einstein. Ela afirma que a Terapia do Riso nos hospitais é capaz levantar o alto astral do paciente e diminuir o sofrimento da internação, deixando-o mais confiante.

A psicóloga Fátima conta que o sorriso traz uma série de sensações agradáveis e ajuda a eliminar sensações negativas, como tristeza e, até mesmo, depressão.

\section{ANEXO B}

Riso e saúde

Já sabemos há muito tempo que rir é útil para aqueles que enfrentam uma doença grave e o estresse dos problemas da vida. Mas os pesquisadores agora dizem que o riso pode fazer muito mais. Basicamente, ele pode trazer equilíbrio a todos os componentes do sistema imunológico, sistema que nos ajuda a lutar contra as doenças.

Como mencionamos anteriormente, a risada reduz os níveis de certos hormônios do estresse. Ao fazer isso, a risada fornece uma válvula de segurança que fecha o fluxo dos hormônios do estresse e da resposta biológica ao perigo, que se transforma em ação nos nossos corpos quando experimentamos o nervosismo, a raiva ou a hostilidade. Estes hormônios do estresse suprimem o sistema imunológico, aumentando o número de plaquetas no sangue (o que pode causar obstrução nas artérias) e faz subir a pressão arterial. Quando estamos rindo, as células matadoras naturais que destróem tumores e vírus aumentam, assim como o interferon gama (proteína que ataca as doenças), as células $T$, parte mais importante da resposta imunológica e as células $B$, que produzem os anticorpos.

O riso pode provocar soluço e tosse, que limpam o trato respiratório ao desalojar os tampões de muco. O riso também aumenta a concentração de imunoglobulina A salivar, que faz a defesa contra organismos infecciosos que entram pelo trato respiratório.

O que pode surpreendê-lo ainda mais é o fato de que os pesquisadores estimam que rir cem vezes é igual a dez minutos no aparelho de remo seco ou quinze minutos na bicicleta. Rir pode ser uma sessão completa de ginástica para o corpo! A pressão arterial abaixa e há um aumento no fluxo e na oxigenação do 
sangue, o que também auxilia na cura. A risada também fornece ao seu diafragma e abdômen, aparelho respiratório, face, pernas e músculos das costas uma sessão de ginástica. Isto explica porque você geralmente se sente cansado após um longo ataque de riso; você acabou de fazer ginástica aeróbica!

Os benefícios psicológicos do humor são surpreendentes, afirmam os médicos e enfermeiras membros da American Association for Therapeutic Humor (em inglês). Geralmente, as pessoas guardam emoções negativas tais como raiva, tristeza e medo, ao invés de expressá-las. O riso possibilita uma maneira destas emoções serem liberadas inofensivamente. A risada funciona como catarse. Por isso algumas pessoas tristes ou estressadas vão ao cinema ou ao teatro para assistir a uma comédia, para que elas possam rir até mandar as emoções negativas embora (estas emoções, quando guardadas, podem causar mudanças bioquímicas que afetam nosso organismo).

Cada vez mais os profissionais de saúde mental estão sugerindo a "terapia do riso", que ensina às pessoas como rir abertamente de coisas que normalmente não são engraçadas, e a enfrentar situações difíceis usando o humor. Seguindo o exemplo real do engraçado Dr. Patch Adams (interpretado por Robin Williams no filme "Patch Adams - O amor é contagioso"), os médicos e psiquiatras estão se tornando mais conscientes dos benefícios terapêuticos da risada e do humor. Isto se deve, em parte, ao crescente grupo de estudiosos do humor e da risada (500 acadêmicos de diferentes disciplinas pertencem à International Society for Humor Studies).

Aqui vão algumas dicas para você acrescentar mais riso à sua vida:

descubra o que faz você rir e faça isto (ou leia ou assista isto) mais frequentemente;

cerque-se de pessoas engraçadas e esteja com elas sempre que puder;

desenvolva o seu próprio senso de humor. Você pode até ter aulas para aprender como ser um humorista melhor ou pelo menos um contador de piadas melhor na próxima festa. Seja engraçado sempre que puder, contanto que não seja às custas de alguém.

\section{ANEXO C}

Um sorriso largo garante uma vida longa, revela estudo

Quanto mais profundos os vincos em volta dos olhos quando se sorri, mais longa será a vida do indivíduo.

Quanto mais largo o sorriso e mais profundos os vincos em volta dos olhos quando se sorri, mais longa será a vida do indivíduo, revela um estudo publicado esta semana na revista Psychological Science.

Cientistas chefiados por Ernest Abel, da Universidade Wayne State, em Michigan, estudaram 230 fotos de jogadores da principal liga de beisebol americana que começaram a jogar antes de 1950 e as agruparam de acordo com os tipos de sorriso.

Os jogadores foram classificados segundo os critérios "sem sorriso" - quando apenas olhavam inexpressivamente para a câmera -, "sorriso parcial" - quando o 
sorriso envolvia apenas os músculos ao redor da boca - ou "sorriso total", quando o sorriso envolvia a boca, os olhos e ambas as bochechas pareciam levantadas.

As fotos foram tiradas do Registro de Beisebol de 1952, uma lista de informações profissionais com dados e estatísticas sobre os jogadores, como ano de nascimento, índice de massa corporal, estado civil e tempo de carreira, os quais refletem a forma física.

O volume de estatísticas permitiram aos cientistas controlar outros fatores que poderiam afetar a expectativa de vida dos jogadores.

Entre os jogadores falecidos a partir de 10 de junho do ano passado, os da categoria "sem sorriso" viveram uma média de 72,9 anos, os com "sorriso parcial", 75 anos, e os de "sorriso total" viveram, em média, 79,9 anos, demonstrou o estudo.

"Considerando que a intensidade do sorriso reflete uma disposição emocional interna, os resultados deste estudo correspondem aos de outros que demonstram que as emoções têm um vínculo positivo com a saúde mental, física e a longevidade", destacou.

No entanto, não ficou claro para os pesquisadores se os jogadores sorriram espontaneamente ou se o faziam a pedido de algum fotógrafo.

De qualquer forma, a proporção de indivíduos com sorriso largo - 23 - foi muito menor a daqueles com sorriso parcial ou sem sorriso (64 e 63, respectivamente), o que indica para os cientistas que mesmo que os sorrisos tenham atendido a um pedido, sua intensidade refletiu a "disposição geral interna" do jogador.

Recebido: 30 out. 2015

Aprovado: 26 jan. 2017

DOI: $10.3895 /$ rl.v12n25.3254

Como citar: SOUSA, W.K.M.V.; FERNANDES, E.M.da FONSECA. O riso e o corpo: reflexões acerca do riso e sua relação

com o biopoder. R. Letras, Curitiba, v. 18, n. 23, p. 36-55, jul./dez. 2016. Disponível em:

$<$ https://periodicos.utfpr.edu.br/rl>. Acesso em: XXX.

Direito autoral: Este artigo está licenciado sob os termos da Licença Creative Commons-Atribuição 4.0 Internacional.

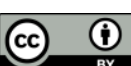

